\title{
Cultural Differences and Common Regional Challenges for e-Commerce in Asia-Pacific Region
}

Agon Memeti ${ }^{1}$, Gazmend Xhaferi ${ }^{2}$

Teaching Assistant - State University of Tetovo, Macedonia ${ }^{1}$ agon.memeti@unite.edu.mk ${ }^{1}$

Teaching Assistant - State University of Tetovo, Macedonia ${ }^{2}$

\section{ABSTRACT}

gazmend.xhaferi@unite.edu.mk ${ }^{2}$

Taking in consideration that the rapid growth using online services last few years becomes more necessary all over the world and on the other side since the internet revolution, it seemed important and useful for all online both sellers and buyers the online shopping. This review starts will cultural and regional challenges in Asia-Pacific Region by examining issues, which are relevant to sites, targeted to China and Chinese-speaking audiences, design principles as well as examination of the differences between the cultures of Asia-Pacific; continuing will issues and influences of e-commerce and online shopping in India for the last few years. Finally, how CRM is becoming the next goal of e-commerce for both smaller and larger organizations is discussing by which it will satisfy customers and increase company sales.

\section{Keywords}

E-commerce; online services; online shopping; CRM.

\section{Academic Discipline And Sub-Disciplines}

Computer Sciences; e-Commerce

\section{SUBJECT CLASSIFICATION}

Computer Science Subject Classification

\section{TYPE (METHOD/APPROACH)}

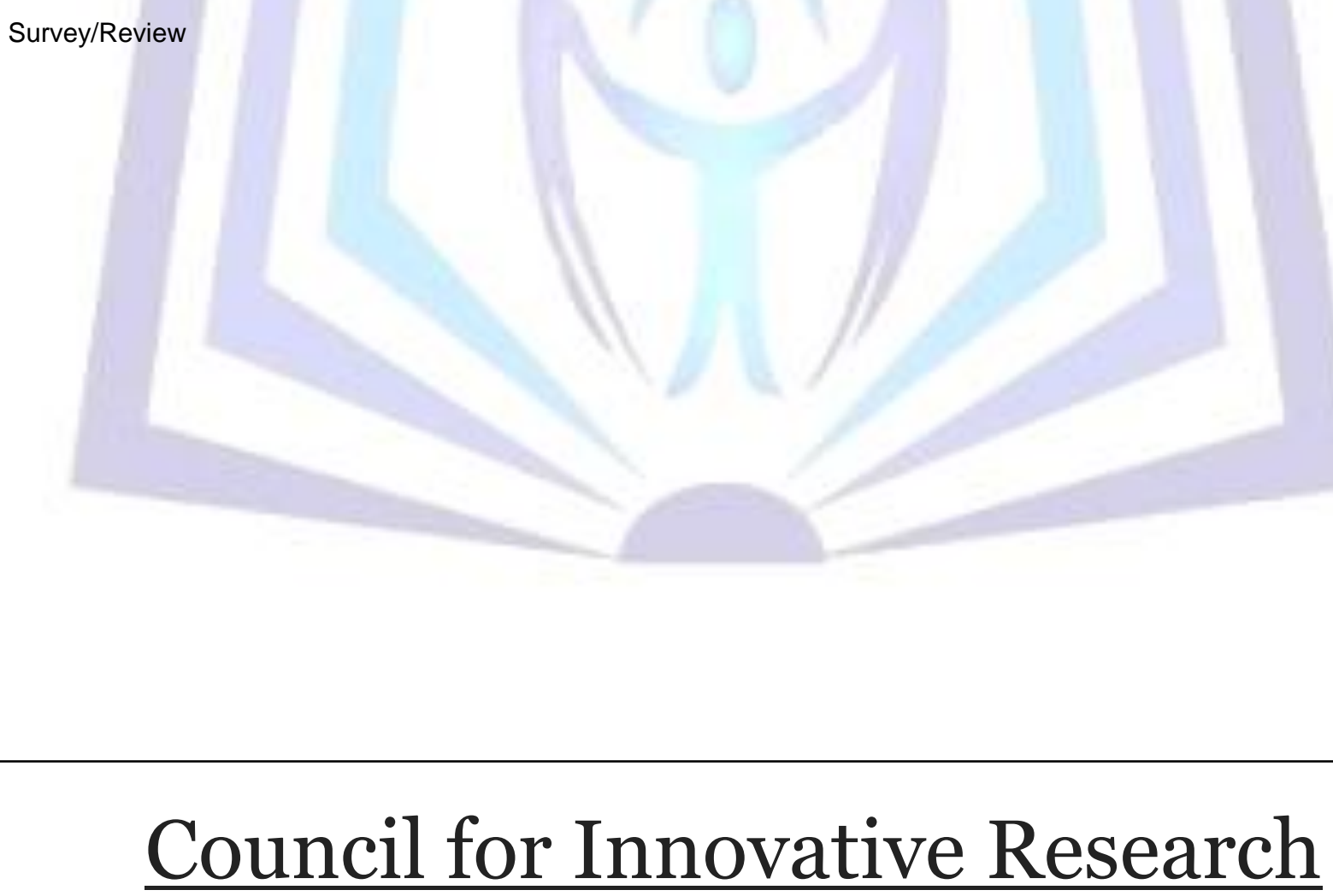

Peer Review Research Publishing System

\section{Journal: INTERNATIONAL JOURNAL OF COMPUTERS \& TECHNOLOGY}

Vol 14 . No. 4

www.ijctonline.com, editorijctonline@gmail.com 


\section{INTRODUCTION}

Asia-Pacific Region online market is highly developed and has become too big for international businesses to ignore. Giving the growing importance and huge potential of the countries retail industry, foreign investors are keen to tap into this lucrative market.

After a slow start in the beginning where there was a tremendous potential but with many differences. Starting between: cultures, society impact the design and content of web sites, limited use of Credit Cards, lack of trust both in the online retailers and in the concept of baying something without face to face contact, lack of trust of providing personal information's, etc.

The industry took off around 2004 as a new payment mechanisms (predominantly: Ali pay) and Alibaba's platform (Taobao and Alibaba) began to catch the attention of the fast growing number of internet and mobile phone users. The ecommerce market has grown rapidly over the last few years in Asia-Pacific, spurred on by the advent of third party platforms such as "Taobao" and third party payment systems, which have made consumers more at ease with spending online, feeling safe and secure in context to give their detail and payments. Although sales are definitely most important task but a post sale support for Customer Relationship Management is becoming as important as this, because brings customers back by managing a company interactions with current and future customers, providing better services, deals sales, discovers new customers, and help sales.

\section{CRITICAL EVALUATION}

According to Jeffrey Hsu in his book chapter "Targeting E-Commerce to Chinese Audiences and Markets: Managing Cultural and Regional Challenges" the start of online shopping in China although with tremendous potential there where so many cultural and regional challenges starting by China-speaking audiences including users and consumer behavior patterns, design principles and differences between cultures of China, Taiwan, Hong Kong and Singapore. Many experts predicted that China would have the second largest population of web-surfers after the United States based on internet population, which was doubling every six month, by (CNNIC 2001). Chinese market may involve into one of the largest in the world. There were 210 million Internet users in 2008 and the top five nations in terms of Internet use according to Jeffrey Hsu.

Cultural and social aspects of China influence the design and content of web pages, resulting in many issues, starting from the difference between Chinese and American / Western cultures, family, region and color. In my opinion, this was the key problem of e-commerce and online shopping in the first years in Asia-Pacific.

The influence of culture was the important factor in determining the success of web site or e-commerce business, and culture not only material features of human environment but beliefs, science, regions and law related to the perceptions and attitudes, which a group of people or a country had about money and mutual trust between customers and merchants towards institutions: banks and government. In addition to the culture, it was fundamentally the importance of marketing aspects (Mooij - 1998) and the success or failure may depend on effectively employing cultural elements. Well-known major studies into culture were Geert Hofstede's Dimensions cultures. The work conducted at IBM in 53 countries referenced in the same article. The theory, developed from this data, as explained in the same article, used to form five cultural dimensions:

- Power Distance - which one refers to the amount of inequity, or imbalance between those with power and those without within a culture;

- Collectivism versus Individualism - whether the culture was focused more towards the individual or towards a collective group (Collective - needs of society or group over the individual laws and regulations);

- Femininity versus Masculinity - their influence in the country's culture: Masculinity(aggressiveness, competition, career enhancement) and Femininity(family, modesty, quality of life) according China masculine culture(1997); uncertainly avoidance - how much stress or anxiety is generated by unknown or uncertain events based on that, that China is high on the scale in terms of avoidance.

These were some characteristics by which their applications were used in designing more web sites that are effective, according the study. Differences between China, Taiwan, and Hong Kong according Hofstede's Dimensions were that China and Hong Kong exhibit higher levels of long-term orientation and masculinity compared with Taiwan and Taiwan tends to show signs of having higher levels of uncertainly avoidance and individualism than Hong Kong or China, according to the book chapter. As far as the Chinese culture compared with Western is concern, according to Jeffrey Hsu chine's culture effects and differs a lot in terms of web design which is intuitive, aesthetic, aggressive, depended, implicit and group-oriented, on the other side western is relational, scientific, independent, active and change oriented. Unlike US and other Western cultures, Confucianism influenced China culture in which societal harmony and respect for family and elders are important.

According to a study by Lai (2001) in the same article, many Chinese Internet users are more interested in and concerned with the news and information which relates to their immediate geographic area, and because of this the language is a key factor based on tradition and pride being Chinese. Most of e-commerce users were from major cities, more interest urban areas. Users less than 25 years of age including students and professional employment in government or industry which were interested on buying books and audio CD, which was low, priced, only a $20 \%$ of population has done shopping online. 
Another key factor was the limited use Credit Cards in China, which contributes to making e-commerce transactions more difficult than in US and Europe. The problem was due to a lack of trust both in the online retailers and in the concept of buying something without face-to-face contact and without relationship. Privacy and security more acute among Chinese: lack of trust of providing personal information has; lack of trust in security of credit cards; banking system and government in general. They were using cash on delivery mostly, credit cards were insecure and not widely in use according (Ortolani, 2005).

The design aspect of Chinese websites, also was a factor firstly they were using red and black color; pay layout with so many animations and banners other than American sites; and the site content was information oriented in terms of interactivity.

Lastly, differences between major and Chinese speaking regions contributed on the low usage of online shopping, starting by the fact:

- $\quad$ China - Internet users were young (educated) and preferred to surf internet in Mandarin Chinese (understand and use their language using simplified Chinese characters);

- Hong Kong - there is a cosmopolitan nature (British Influence) - use of English is more widespread, two languages in one site (English and Chinese);

- Taiwan - it's a use of traditional Chinese characters;

- $\quad$ Singapore - its likely Hong Kong were books and computer products are on the top purchases online and use of Slang called "Singlish" - combination of English with Malay and Mandarin Chinese.

All-important brands moved into online shopping and get benefited both sellers and buyers. Every big company adopted the e-commerce technology and make branding all over the globe, about $128 \%$ growth in interest from consumers on 2012, according Anukrati Sharma and, 40\% growth between 2010 and 2011(according a Google Report), referenced in the same book chapter. Both urban and rural populations are using internet facilities and most of them interested online on: Books, Beauty \& Personal Care, Home \& Furnishing, Baby products and Healthcare. According to Sharma study of recent trends, influences towards e-commerce on online shopping and suggestions for improvement by making a questionnaire and collecting data, also interviews by 250 respondents and secondary data by various websites and books reasons of growth of e-commerce were:

- Busy Lifestyle - unable to go to crowded markets every time for shopping;

- High Disposable Income - according the growing job opportunities;

- Awareness of Products - aware about new products, product features, availability and price;

- Rising Computer Educational Level - computer education getting new horizons, much more aware regarding the tools and techniques;

- Increased Usage of Internet - more than 100 million Internet users; and

- Easy to Find and Review of Products - getting information about products and of course according the online shopping effectives such us:

- Security - customers want to be safe and secure;

- Easy and Understandable Content - understandable and easy language website;

- Deliver of High and Quick Quality Services and Combination of Branded Products and Non-Branded Products.

Based on these facts we think that online shopping differs a lot from traditional shopping, starting by:

- Having Product Detailed Descriptions;

- Search Functions;

- Special Offers and the most important

- Shopping online $24 / 7$.

The Sharma survey showed that $32.5 \%$ of age group was 21-30 years old; female respondents were 180 higher than the male respondents 70 were. Monthly income of maximum people who shop online was in the range between $40,000-$ 50,000 ; the educational level of online buyers where post graduate level because of the fact that they are able to understand the language, content, terms and conditions of the product while they are shopping online.

According to the answer of most preferred website, $23.6 \%$ where interested and preferred Homeshop, and most of them preferred buying weekly at about $29,6 \%$, which were more interested on clothing and accessories; and most important they are feeling secure (around 65.2\%) in context to give their details and payments but prefer mostly, about $27.6 \%$ cash on delivery. 
Taking in consideration the Sharma's report, we think that Asia-Pacific is going to have a huge and growing number of consumers willing to shop online. My opinion is that they are shifting cultural and regional challenges by feeling safer providing personal information; trusting e-commerce web sites; especially platform web sites and notably Alibaba and Taobao, have played a prominent role in booking online consumption and payments systems such as Alipay have done to reduce fears of buying online.

According to us issues of e-commerce and online shopping in Asia-Pacific are:

- Shopping Trends

- Rise of Access Channels;

- Increase in B2C Business - gaining momentum and we think it will a large percentage of the market in the next few years;

- Government Regulations and Compliance

- More Geographic Spread - a vital issue; and most important

- Fixing Logistics - late delivery, negative attitudes from delivery peoples and working hard to establish customer trust fixing cash on delivery.

Even though sales are definitely most important task but a post sale support for Customer Relationship Management $(\mathrm{CRM})$ is becoming as important as this, because brings customers back by managing a company interactions with current and future customers. It helps business market and sell their product more effectively, also through CRM implementation the data integration would provide a universal view of the customer by removing data deficiencies(such as wrong numbers, incorrect addresses) and also help summarize customer data.

As we mentioned before the next goal of e-commerce web sites it would be the CRM and its maintenance. As NetSuite Inc, Berlin Packaging Churchill Downs and others explain in the "The secret to CRM is in the Data", a Real World Case. It helps the organization in lots of ways, both in terms of delivery more to the customers and in terms of gaining more from them by:

- Providing Better Customer Service - giving the ability to personalize relationship with customers regardless of which employee is service them, maintenance of customer profiles by which every employee can be better informed about each customer's specific needs, adjust the level of service to reflect the customer's importance or status;

- Discover New Customers - identifying potential customers;

- Cross Sell and Up Sell Products More Effectively - offering customers suggestions(complimentary) products based on their previous purchases and offering products in the same category;

- Help Sales Staff Close Deals Faster - quicker and more efficient Reponses to customer leads and customer information;

- Simplify Marketing And Sales Processes - better communication channels.

Both smaller and larger organizations are in position to be effective users of CRM by having the data organized, which enable the business easily to analyze all information has and gain clear understanding preferences of customers, satisfying them and a profitable business in the same time. CRM will be the system to precede input data then to give information has to increase sales of the company. This is why, one of the main issues noted in the case is the importance of "good" data for the success of CRM implementations by file processed and approached database management.

\section{IMPACT AND QUESTIONS}

The main article has high impact about the study for Asia-Pacific Regions but there are not any comparative analyses for European cultural differences and US case studies.

1. Is it the technology or the targeted market the reason for success in e-Commerce nowadays?

2. Are the alternative e-commerce channels (social media, mobile, chat) foreseen as advantage or disadvantages?

3. Are the sales important or the post sales support is also taking a step forward in increasing the sales (profit)?

\section{CONCLUSION}

By giving in depth information about cultural differences and common regional challenges for e-commerce in Asia-Pacific region and making business online especially starting from a low base a decade ago and now a days, people are increasingly willing to conduct online transactions.

I conclude that online shopping and e-commerce are an important part of B2B and B2C in the present world but the next goal of online companies it will be the importance of "good" data of CRM considering that without accurate, complete, and comprehensive data, any CRM efforts inside online companies will be less than optimal. That eventually will make customers become returning customers. 


\section{REFERENCES}

[1] Gianni, Origoni, Grippo \& Partners; E-commerce in China: a booming market within a booking market; Intelectual Property; August,2011.

[2] Serge Hoffmann, Bruno Lannes and Jessica Dai: Heading toward RMB 1.5 trilio; 2012.

[3] A.T.Kearney; China's E-commerce Market: The Logistics Challenges;2011.

[4] Jin Guming;Chinas B2C E-commerce development and its future prospects; April, 2012.

[5] Hongxiu Li, Reima Soumi; E-commerce development in China: opportunities or challenges?

[6] EUSME Report; Selling online in China; 2012.

[7] Mc Kinsey Global Institute; China's e-tail revolution: Online Shopping as a catalyst for growth; March, 2013. 